Review

\title{
Gait kinetics in children with clubfeet treated surgically or with the Ponseti method: A meta-analysis
}

\author{
A.B.M. Tuinsma ${ }^{\mathrm{a}}$, B. Vanwanseele ${ }^{\mathrm{b}, \mathrm{c}}$, L. van Oorschot $^{\mathrm{b}}$, H.J.J. Kars ${ }^{\mathrm{b}}$, L. Grin ${ }^{\mathrm{b}}$, M. Reijman ${ }^{\mathrm{d}, \mathrm{e}}$, \\ A.T. Besselaar ${ }^{\mathrm{a}, \mathrm{d}}$, M.C. van der Steen ${ }^{\mathrm{a}, *}$ \\ ${ }^{a}$ Department of Orthopaedic Surgery, Catharina Hospital Eindhoven, Postbus 1350, 5602 ZA, Eindhoven, The Netherlands \\ ${ }^{\mathrm{b}}$ Department of Health Innovation and Technology, Fontys University of Applied Sciences, Ds Theodor Fliednerstraat 2, 5361 BN, Eindhoven, The Netherlands \\ ${ }^{\mathrm{c}}$ Department of Kinesiology, KU Leuven, Tervuursevest 101, 3001, Heverlee, Belgium \\ d Orthopaedic Center Máxima, Máxima Medical Center, Postbus 90052, 5600 PD, Eindhoven, The Netherlands \\ e Department of Orthopaedic Surgery, Erasmus MC, University Medical Centre, Postbus 2040, 3000 CA, Rotterdam, The Netherlands
}

\section{A R T I C L E I N F O}

\section{Keywords:}

Clubfoot

Ponseti method

Surgical treatment

Functional outcome

Kinetics

\begin{abstract}
A B S T R A C T
Background: Currently, the Ponseti method is the gold standard for treatment of clubfeet. For long-term functional evaluation of this method, gait analysis can be performed. Previous studies have assessed gait differences between Ponseti treated clubfeet and healthy controls.

Research question/purpose: The aims of this systematic review were to compare the gait kinetics of Ponseti treated clubfeet with healthy controls and to compare the gait kinetics between clubfoot patients treated with the Ponseti method or surgically.

Methods: A systematic search was performed in Embase, Medline Ovid, Web of Science, Scopus, Cochrane, Cinahl ebsco, and Google scholar, for studies reporting on gait kinetics in children with clubfeet treated with the Ponseti method. Studies were excluded if they only used EMG or pedobarography. Data were extracted and a risk of bias was assessed. Meta-analyses and qualitative analyses were performed.

Results: Nine studies were included, of which five were included in the meta-analyses. The meta-analyses showed that ankle plantarflexor moment ( $95 \%$ CI -0.25 to -0.19 ) and ankle power (95\% CI -0.89 to -0.60 , were significantly lower in the Ponseti treated clubfeet compared to the healthy controls. No significant difference was found in ankle dorsiflexor and plantarflexor moment, and ankle power between clubfeet treated with surgery compared to the Ponseti method.

Significance: Differences in gait kinetics are present when comparing Ponseti treated clubfeet with healthy controls. However, there is no significant difference between surgically and Ponseti treated clubfeet. These results give more insight in the possibilities of improving the gait pattern of patients treated for clubfeet.
\end{abstract}

\section{Introduction}

A clubfoot (talipes equinovarus) is a three dimensional congenital deformity of the foot involving equinus, varus, adductus, and cavus [1]. The goal of treatment is to correct clubfeet and come to a functional, pain-free foot with good mobility and no need to wear modified shoes [2]. Initial severity and short-term treatment success is often evaluated with the Pirani and/or Dimeglio score [3,4]. For long-term functional evaluation of treatment gait analysis focusing on gait kinetics and kinematics is frequently applied [5]. Gait kinematics describe the motion of body segments during the stance and swing phase of the gait cycle [6]. This includes the position and orientation of body segments, the angles of the joints, and the corresponding velocities and accelerations
[6]. Gait kinetics give information about the contribution of the muscle groups to a movement and is often reported as joint moment, power, and work [6]. Joint moments determine the amount of force that is produced by a muscle group around a joint and are defined as the force multiplied by the moment arm of the muscle. Work in a joint is the mechanical energy produced by the muscle during a movement. Joint power is the rate at which this mechanical energy is produced. Differences in gait characteristics can lead to an impaired gait pattern, including a lower walking speed, impaired push-off, and less balance [7-9]. Information on impaired gait characteristics are important for setting out targeted treatment for the patient, for example physiotherapy or secondary surgery.

Previous studies show that clubfeet initially treated by extensive

\footnotetext{
* Corresponding author at: Department of Orthopaedic Surgery, Postbus 1350, 5602 ZA, Eindhoven, The Netherlands

E-mail address: marieke.vd.steen@catharinaziekenhuis.nl (M.C. van der Steen).
} 
surgery - i.e., posteromedial release - show differences in gait kinematics and kinetics compared to healthy controls [10-12]. Differences in gait kinetics include for example lower ankle plantarflexor moment and lower ankle power [13-16]. Nowadays, the Ponseti method is the gold standard for the treatment of clubfeet $[17,18]$. The Ponseti method is a less-invasive method that uses several plaster casts, mostly combined with an Achilles tenotomy, followed by a brace period until the age of four to maintain the foot in the corrected position [12]. High success rates based on clinical examinations and surveys, including a functional foot with good mobility, are reported as the outcome of the Ponseti treatment [19-22]. However, small but distinct differences in gait kinematics and kinetics compared to healthy controls do exist [e.g., $[23,24]$. It is unclear what causes the differences in gait kinetics between treated clubfeet patients (surgical or with the Ponseti method) and controls. Lower ankle power and ankle moment could be secondary to triceps surae insufficiency as a result of surgical interventions $[12,25]$. Furthermore, these kinetic differences could also be influenced by a lower ankle range of motion, for example as a result of a flat top talus [26].

A clear systematic overview of the effectiveness of the Ponseti method in terms of long-term correction of clubfeet and resulting in a functional, pain-free foot with good mobility and no need to wear modified shoes, is not available yet. Several studies assessed differences in gait characteristics, between children treated for clubfeet with the various methods and between children treated for clubfeet and healthy controls, as a measure of functional outcome of clubfoot treatment. This systematic review aims to (1) determine the differences in gait kinetics between children treated for clubfoot deformities with Ponseti and healthy controls and (2) determine the differences in gait kinetics between clubfoot patients treated with the Ponseti method or by extensive surgery, in an attempt to give more insight in the functional outcome of the Ponseti method as primary treatment for clubfeet.

\section{Methods}

\subsection{Protocol and registration}

The systematic review was reported and conducted according to the PRISMA (Preferred Reporting Items for Systematic reviews and MetaAnalyses) guidelines $[27,28]$. Study protocol was registered with International Prospective Register of Systematic Reviews (PROSPERO) with registration number CRD42015029715.

\subsection{Eligibility criteria}

Randomized Controlled Trials, retrospective and prospective followup studies, and cross-sectional studies comparing kinetic gait parameters of patients with clubfeet with healthy controls or comparing kinetic gait parameters of clubfoot patients treated with different interventions were considered. Studies were only included if they studied at least clubfeet treated with the Ponseti method. A minimum number of five participants per group was set. Studies using only pedobarography or EMG and systematic reviews or conference abstracts were excluded.

\subsection{Information sources and search}

An experienced information specialist performed the systematic search, until June $8^{\text {th }} 2018$ in Embase, Medline ovid, Web of Science, Scopus, Cochrane, Cinahl ebsco, and Google scholar (Appendix A shows the full Embase search as an example). Language was restricted to English, Dutch, and German. Search terms comprised of synonyms of clubfeet, treatment, gait analysis, and children. Furthermore, references of all included studies were manually searched. Duplicated articles were removed prior to study selection.

\subsection{Study selection}

Titles and abstracts of the search results were assessed for eligibility by two independent researchers (LO and MS). In a second step, full text of selected articles were checked for in- and exclusion criteria. A third reviewer (HK) was consulted in case of absence of consensus after reading the full text articles.

\subsection{Data collection process and data items}

One data extraction form was created and used by two researchers (MS and MT) to extract data of the included studies. Besides study characteristics, all reported kinetic outcome measures of the included studies were extracted. The main outcome measures were internal joint moment, impulse, power and work at the ankle, knee, and hip. A third researcher (LG) checked the extracted data for accuracy.

\subsection{Risk of bias in individual studies}

Two reviewers (MR and BV) independently assessed the individual studies for risk of bias. The Dutch checklist form for prognosis (Cochrane Netherlands) was used, applied with modifications to the items set to relevance of the current study objectives. Table 1 represents the risk of bias summary including checklist items. Items could be scored with 'low risk' (+), 'high risk' (-), or 'unclear' (?). The forms were then compared and discussed for final consensus.

\subsection{Data syntheses and analysis}

Qualitative synthesis in which outcomes were compared in a descriptive manner was performed on outcome measures discussed in two or less studies. Outcome measures reported in at least three studies

Table 1

Risk of bias of the included studies.

\begin{tabular}{|c|c|c|c|c|c|}
\hline & $\begin{array}{l}\text { No participant selection } \\
\text { took place }\end{array}$ & $\begin{array}{l}\text { Groups are comparable } \\
\text { regarding age }\end{array}$ & $\begin{array}{l}\text { Validated measuring } \\
\text { system used }\end{array}$ & $\begin{array}{l}\text { Independent (blind) determination } \\
\text { of outcomes }\end{array}$ & $\begin{array}{l}\text { Clear description of groups } \\
\text { available }\end{array}$ \\
\hline Church 2012 [12] & + & + & + & ? & $?$ \\
\hline Duffy 2013 [29] & $?$ & - & + & $?$ & - \\
\hline Jeans 2015 [24] & $?$ & + & + & - & + \\
\hline Karol 2009 [30] & - & + & + & $?$ & + \\
\hline Lööf 2016 [33] & $?$ & + & + & $?$ & $?$ \\
\hline Lööf 2017 [34] & $?$ & + & + & $?$ & + \\
\hline Manousaki 2016 [25] & + & $?$ & + & ? & $?$ \\
\hline Mindler 2014 [31] & $?$ & + & + & $?$ & $?$ \\
\hline Smith 2014 [32] & - & - & + & - & - \\
\hline
\end{tabular}

$+:$ low risk.

-: high risk.

?: unclear. 


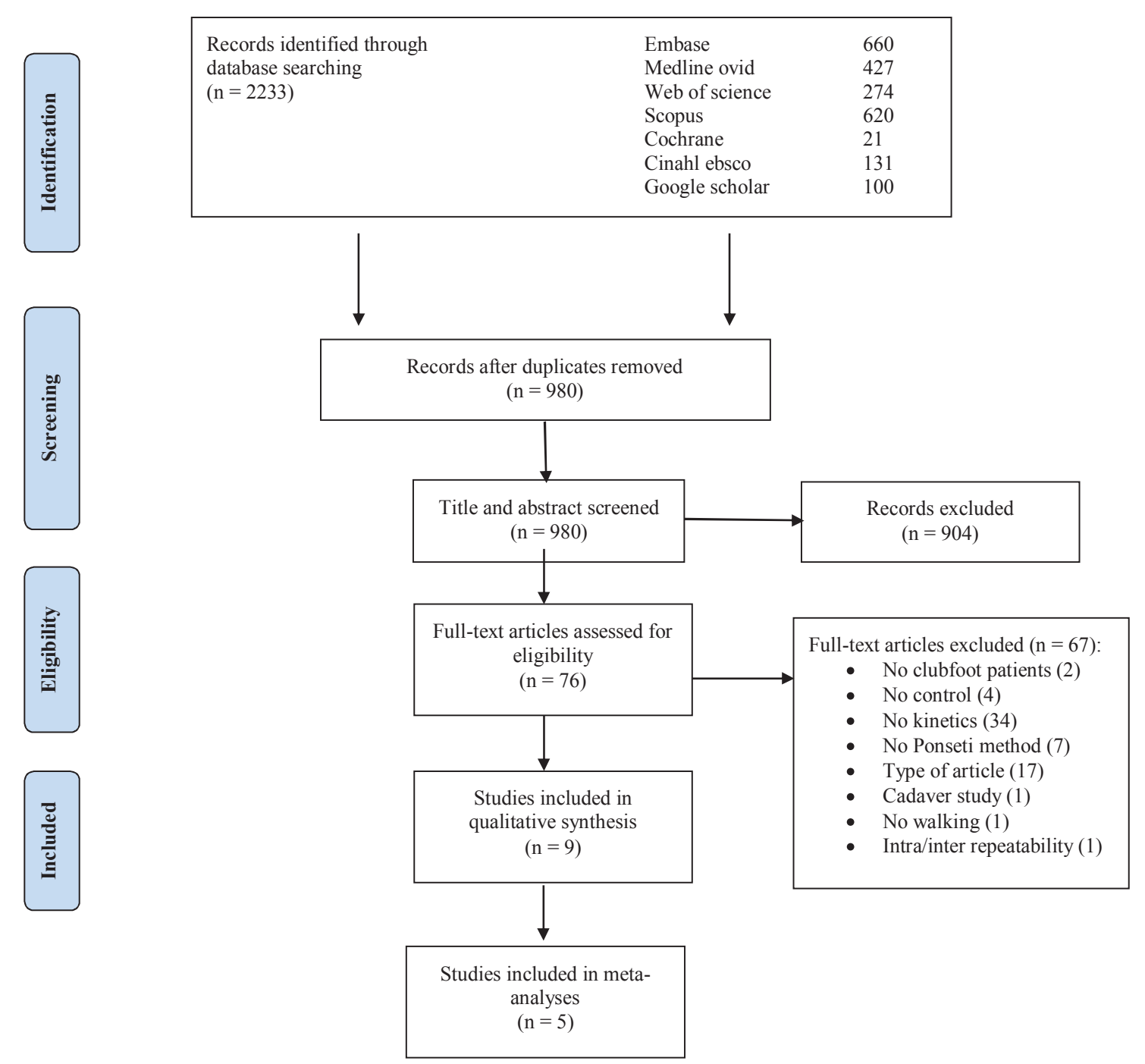

Fig. 1. Study flow diagram.

were included in the meta-analyses performed with Review Manager (RevMan) [Computer program Version 5.3. Copenhagen: The Nordic Cochrane Centre, The Cochrane Collaboration, 2014]. The consistency of results was estimated with $\mathrm{I}^{2}$ statistics. $\mathrm{I}^{2}$ values of $0 \%-30 \%$ were interpreted as no to low heterogeneity, $30 \%-50 \%$ as moderate heterogeneity, $50 \%-75 \%$ as substantial heterogeneity, and $>75 \%$ as considerable heterogeneity. A p-value $<0.05$ indicated high importance of the $\mathrm{I}^{2}$-value. When there was no significant statistical heterogeneity, the fixed effects model was used. The random effects model was used when there was statistical heterogeneity $\left(\mathrm{I}^{2}>50 \%\right.$ and $\mathrm{p}<0.05)$.

\section{Results}

\subsection{Study selection and characteristics}

The initial search resulted in 980 records, of which 9 studies [12,24,25,29-34] were included for the qualitative synthesis and 5 in the meta-analyses [25,29-31,33] (see Fig. 1). All included papers were published in English. In two studies [33,34], data was presented separately for uni- and bilateral affected clubfeet patients and both groups were compared with the same control group. In the current analyses, data of clubfeet patients was combined via RevMan Calculator and considered as a single study (see also discussion). Table 2 displays the study characteristics and relevant outcome parameters of the included studies. In all studies, Achilles tenotomy during the casting phase was seen as part of the Ponseti treatment. Participants included in the surgical treatment groups underwent a wide variety of surgical interventions as treatment for their clubfoot (e.g. posteromedial releases, tendon transfers and cuboid osteotomy). Selection of participants was mostly unclear (see Table 1).

\subsection{Risk of bias within studies}

Table 1 represents the risk of bias summary including checklist items and the final risk classification for each study. Although validated measuring systems were used to acquire the data, all studies showed unclear or high risk of bias on one or more items of the checklist.

\subsection{Clubfeet treated with Ponseti versus healthy controls}

Nine studies compared kinetic variables for clubfeet patients treated with the Ponseti method to healthy controls [12,24,25,29-34]. Five of these studies were used in the meta-analyses [25,29-31,33] comparing peak ankle plantarflexor moment and peak ankle power between Ponseti and control. Fig. 2 shows the results of the meta-analyses. Ankle plantarflexor moment and ankle power were significant lower in the Ponseti treated clubfeet compared to controls. The study by Church et al. [12] was excluded from the meta-analyses since the reported values for ankle plantarflexor moment and ankle power were 
Table 2

Study characteristics and reported outcome measures of included studies.

\begin{tabular}{|c|c|c|c|c|c|c|}
\hline Study & Treatment & $\begin{array}{l}\text { Number of } \\
\text { feet }\end{array}$ & $\begin{array}{l}\text { Gender (Male, } \\
\text { Female) }\end{array}$ & $\begin{array}{l}\text { Age in years, mean } \\
\pm \text { SD or mean } \\
\text { (range) }\end{array}$ & $\begin{array}{l}\text { Outcome measures included } \\
\text { in meta-analysis }\end{array}$ & $\begin{array}{l}\text { Outcome measures included } \\
\text { in qualitative analysis }\end{array}$ \\
\hline \multirow[t]{3}{*}{ Church 2012 [12] } & Ponseti & 35 & $9 \mathrm{M}, 13 \mathrm{~F}$ & $6.3 \pm 1.4$ & Ankle plantarflexor moment & \\
\hline & Surgery (posteromedial release) & 43 & $19 \mathrm{M}, 7 \mathrm{~F}^{*}$ & $9.2 \pm 1.3$ & Ankle power & \\
\hline & Control & $34^{*}$ & $\mathrm{x}$ & $4-17$ & & \\
\hline \multirow[t]{3}{*}{ Duffy 2013 [29] } & Ponseti $^{2}$ & 42 & $20 \mathrm{M}, 9 \mathrm{~F}^{*}$ & $6.5(5.0-8.0)$ & Ankle plantarflexor moment & Ankle work \\
\hline & Surgery (several procedures) & 31 & $20 \mathrm{M}, 3 \mathrm{~F}^{*}$ & $9.1(7.5-10.3)$ & Ankle power & \\
\hline & Control & 52 & $17 \mathrm{M}, 9 \mathrm{~F}^{*}$ & $7.9(5.2-10.8)$ & & \\
\hline \multirow[t]{5}{*}{ Jeans 2015 [24] } & Ponseti & 102 & $\mathrm{x}$ & 5 & Ankle power & \\
\hline & $\begin{array}{l}\text { Ponseti and surgery } \\
\text { (several procedures) }\end{array}$ & 30 & $\mathrm{x}$ & 5 & & \\
\hline & Physical therapy & 83 & $\mathrm{x}$ & 5 & & \\
\hline & $\begin{array}{l}\text { Physical therapy and surgery } \\
\text { (several procedures) }\end{array}$ & 61 & $\mathrm{x}$ & 5 & & \\
\hline & Control & $16^{*}$ & $\mathrm{x}$ & 5 & & \\
\hline \multirow[t]{2}{*}{ Karol 2009 [30] } & Ponseti & 32 & $\mathrm{x}$ & 5 & Ankle plantarflexor moment ${ }^{4}$ & Hip power \\
\hline & Control & 17 & $\mathrm{x}$ & 5 & Ankle power & \\
\hline \multirow[t]{2}{*}{ Lööf $2016^{1}$ [33] } & Ponseti & 89 & $41 \mathrm{M}, 18 \mathrm{~F}^{*}$ & $5.37 \pm 0.43$ & Ankle plantarflexor moment & Knee flexor moment \\
\hline & Control & 56 & $18 \mathrm{M}, 20 \mathrm{~F}^{*}$ & $5.5 \pm 0.6$ & Ankle power & $\begin{array}{l}\text { Ankle dorsiflexor moment } \\
\text { Hip abductor moment }\end{array}$ \\
\hline \multirow[t]{2}{*}{ Lööf $2017^{1}$ [34] } & Ponseti & 69 & $35 \mathrm{M}, 12 \mathrm{~F}^{*}$ & $5.31 \pm 0.45$ & & Gait Deviation Index-Kinetic \\
\hline & Control & 56 & $18 \mathrm{M}, 10 \mathrm{~F}^{*}$ & $5.5 \pm 0.6$ & & \\
\hline Manousaki 2016 & Ponseti $^{3}$ & 30 & $26 \mathrm{M}, 4 \mathrm{~F}$ & $7 \pm 0.3$ & Ankle plantarflexor moment & \\
\hline [25] & Control & 16 & $\mathrm{x}$ & $6.1-12$ & Ankle power & \\
\hline \multirow[t]{2}{*}{ Mindler 2014 [31] } & Ponseti & 50 & $22 \mathrm{M}, 10 \mathrm{~F}^{*}$ & $6(3-8)$ & Ankle power & Hip flexor moment \\
\hline & Control & 28 & $9 \mathrm{M}, 6 \mathrm{~F}^{*}$ & $6(3-9)$ & & Hip abductor moment \\
\hline \multirow[t]{3}{*}{ Smith 2014 [32] } & Ponseti & 29 & $9 \mathrm{M}, 9 \mathrm{~F}^{*}$ & $29.2 \pm 5.6$ & & Ankle power \\
\hline & Surgery (comprehensive release) & 37 & $17 \mathrm{M}, 7 \mathrm{~F}$ & $21.8 \pm 2.3$ & & Hip power \\
\hline & Control & 20 & $29 \mathrm{M}, 19 \mathrm{~F}^{*}$ & $23.2 \pm 2.4$ & & \\
\hline
\end{tabular}

$\mathrm{x}$ : not reported.

* Number of participants, not number of feet.

$* *$ Wording in the original papers for internal joint moments differed. For sake of clarity, throughout this review we refer to internal joint moments is -or.

1 The original papers presents data separately for uni- and bilateral affected feet. The mean age was calculated using the RevMan Calculator See also discussion.

2 Four patients of the Ponseti group also underwent additional surgery.

3 Three feet underwent a posteromedial release.

${ }^{4}$ In the original paper referred to as ankle dorsiflexor moment, but from the context it is clear that the internal ankle plantarflexor moment was reported.

approximately ten times higher than in the other studies. No explanation was given for this by the authors in the paper or as a response to our inquiry emails. In line with the results of the meta-analysis, a significant lower ankle plantarflexor moment and a lower ankle power was shown in Ponseti treated clubfeet compared to the healthy controls [12].

\section{A Ankle plantarflexor moment}

\begin{tabular}{|c|c|c|c|c|c|c|c|c|c|c|c|c|}
\hline Study or Subgroup & \multicolumn{3}{|c|}{ Ponseti } & \multicolumn{3}{|c|}{ Control } & \multicolumn{3}{|c|}{ Mean Difference } & \multicolumn{2}{|c|}{$\begin{array}{l}\text { Mean Difference } \\
\text { N, Fixed, 95\% Cl }\end{array}$} & \\
\hline Duffy 2013 [29] & 0.97 & 0.2 & 42 & 1.15 & 0.2 & 52 & $16.8 \%$ & $-0.18[-0.26,-0.10]$ & & $\longrightarrow$ & & \\
\hline Karol 2009 [30] & 0.74 & 0.11 & 32 & 0.95 & 0.12 & 17 & $23.6 \%$ & $-0.21[-0.28,-0.14]$ & & $\longrightarrow-$ & & \\
\hline Lööf 2016 [33] & 0.8798 & 0.1681 & 89 & 1.1 & 0.13 & 56 & $46.8 \%$ & $-0.22[-0.27,-0.17]$ & & - & & \\
\hline Manousaki 2016 [25] & 0.9565 & 0.1756 & 30 & 1.254 & 0.1409 & 16 & $12.8 \%$ & $-0.30[-0.39,-0.20]$ & & & & \\
\hline Total $(95 \% \mathrm{Cl})$ & & & 193 & & & 141 & $100.0 \%$ & $-0.22[-0.25,-0.19]$ & & & & \\
\hline $\begin{array}{l}\text { Heterogeneity: } \mathrm{Chi}^{2}= \\
\text { Test for overall effect: }\end{array}$ & $\begin{array}{l}66, \mathrm{df}=3 \\
=12.98(\end{array}$ & $\begin{array}{l}P=0.3 \\
P<0.000\end{array}$ & $\begin{array}{l}0) ; 1^{2}= \\
001)\end{array}$ & $18 \%$ & & & & & -0.5 & $\begin{array}{l}-0.25 \\
\text { Decrea }\end{array}$ & Increased & 0.5 \\
\hline
\end{tabular}

\section{B Ankle power}

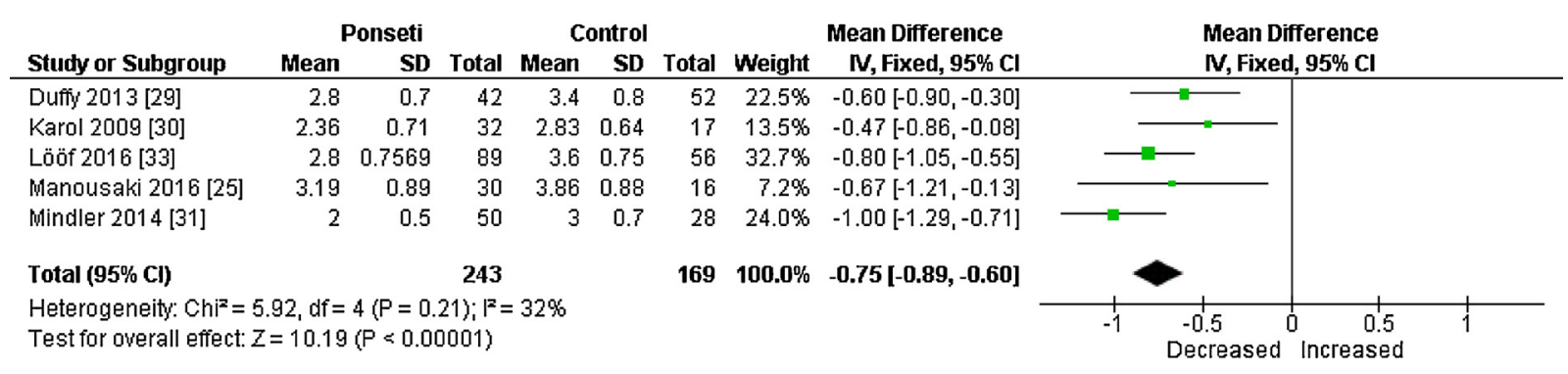

Fig. 2. Meta-analyses comparing Ponseti treated clubfoot patients with healthy controls. 
Table 3

Outcome measures comparing Ponseti treated clubfoot patients with healthy controls included in the qualitative analysis.

\begin{tabular}{|c|c|c|c|}
\hline $\begin{array}{l}\text { Outcome } \\
\text { measure }\end{array}$ & $\begin{array}{l}\text { Difference Ponseti / } \\
\text { control }\end{array}$ & Mean and SD & Study \\
\hline Ankle work & Ponseti $<$ control & $\begin{array}{l}\text { P: } 0.15 \pm 0.5 \mathrm{~J} \\
\text { C: } 0.22 \pm 0.05 \mathrm{~J}\end{array}$ & $\begin{array}{l}\text { Duffy } 2013 \\
\text { [29] }\end{array}$ \\
\hline $\begin{array}{l}\text { Ankle power } \\
\text { (whole gait } \\
\text { cycle) }\end{array}$ & $\begin{array}{l}\text { No significant } \\
\text { difference }\end{array}$ & $\begin{array}{l}\mathrm{P}:{ }^{*} \\
\mathrm{C}:\end{array}$ & $\begin{array}{l}\text { Smith } \\
2014 \text { [32] }\end{array}$ \\
\hline $\begin{array}{l}\text { Ankle dorsiflexor } \\
\text { moment }\end{array}$ & Ponseti $<$ control & $\begin{array}{l}\text { P: } 0.11 \pm 0.07 \mathrm{Nm} / \mathrm{kg} \\
\text { C: } 0.17 \pm 0.06 \mathrm{Nm} / \mathrm{kg}\end{array}$ & $\begin{array}{l}\text { Lööf } 2016 \\
\text { [33] }\end{array}$ \\
\hline $\begin{array}{l}\text { Gait Deviation } \\
\text { Index-Kinetic }\end{array}$ & Ponseti $<$ control & $\begin{array}{l}\mathrm{P}:{ }^{+} \\
\mathrm{C}:{ }^{+}\end{array}$ & $\begin{array}{l}\text { Lööf } 2017 \\
\text { [34] }\end{array}$ \\
\hline $\begin{array}{l}\text { Knee flexor } \\
\text { moment }\end{array}$ & $\begin{array}{l}\text { No significant } \\
\text { difference }\end{array}$ & $\begin{array}{l}\text { P: } 0.20 \pm 0.13 \mathrm{Nm} / \mathrm{kg} \\
\text { C: } 0.25 \pm 0.10 \mathrm{Nm} / \mathrm{kg}\end{array}$ & $\begin{array}{l}\text { Lööf } 2016 \\
\text { [33] }\end{array}$ \\
\hline Hip power & $\begin{array}{l}\text { No significant } \\
\text { difference }\end{array}$ & $\begin{array}{l}\mathrm{P}: 1.38 \pm 0.44 \mathrm{~W} / \mathrm{kg} \\
\mathrm{C}: 1.04 \pm 0.38 \mathrm{~W} / \mathrm{kg}\end{array}$ & $\begin{array}{l}\text { Karol } 2009 \\
{[30]}\end{array}$ \\
\hline $\begin{array}{l}\text { Hip flexor } \\
\text { moment }\end{array}$ & Ponseti $<$ control & $\begin{array}{l}\mathrm{P}:-0.8 \pm 0.2 \mathrm{Nm} / \mathrm{kg} \\
\mathrm{C}:-0.7 \pm 0.1 \mathrm{Nm} / \mathrm{kg}\end{array}$ & $\begin{array}{l}\text { Mindler } \\
2014 \text { [31] }\end{array}$ \\
\hline $\begin{array}{c}\text { Hip abductor } \\
\text { moment }\end{array}$ & $\begin{array}{l}\text { Ponseti }<\text { control } \\
\text { Ponseti }<\text { control }\end{array}$ & $\begin{array}{l}\text { P: } 0.56 \pm 0.13 \mathrm{Nm} / \mathrm{kg} \\
\text { C: } 0.63 \pm 0.14 \mathrm{Nm} / \mathrm{kg} \\
\text { P: } 0.4 \pm 0.1 \mathrm{Nm} / \mathrm{kg} \\
\text { C: } 0.5 \pm 0.1 \mathrm{Nm} / \mathrm{kg}\end{array}$ & $\begin{array}{l}\text { Lööf } 2016 \\
\text { [33] } \\
\text { Mindler } \\
2014 \text { [31] }\end{array}$ \\
\hline
\end{tabular}

$\mathrm{P}=$ Ponseti.

$\mathrm{C}=$ Control.

* No exact values are presented in the original paper, data is presented by a graph.

+ Data in article reported for bilateral and unilateral clubfeet separately, presented as median (range).

Table 3 presents the outcomes for other kinetic variables. Ankle work and ankle dorsiflexor moment were significantly lower in the Ponseti treated clubfeet compared to controls [29,33]. One study compared Gait Deviation Index-Kinetic (GDI-Kinetic) and found a significant lower GDI-Kinetic in the clubfeet group compared to the control group [34]. Two studies compared the hip power. One study found no significant difference [30], whereas the other study found a higher hip power in the Ponseti group compared to controls [32]. One study compared knee flexor moment, but found no significant difference [33]. Ponseti treated clubfeet showed a significant lower hip flexor moment than healthy controls [31]. Two studies found a significant lower ankle abductor moment in Ponseti treated clubfeet compared to healthy controls $[31,33]$.

\subsection{Ponseti versus surgical treated clubfeet}

Three studies compared kinetic variables for Ponseti treated clubfeet with clubfeet patients treated by surgical interventions [12,24,29]. The studied variables were ankle power, ankle plantarflexor moment and ankle work. The results are presented in Table 4. Only one study found a significant larger ankle power in the surgery group compared to the Ponseti group [12]. It should however be notated that there was a difference in age between these two groups. The other two studies found no significant difference in ankle power [24,29]. For ankle plantarflexor moment and ankle work, none of the studies found a significant difference between the two different treatment options $[12,24,29]$.

\section{Discussion}

As far as we are aware, this is the first systematic review on gait kinetics in children with treated clubfeet. When comparing clubfeet treated by the Ponseti method with healthy controls, all studies showed a lower ankle plantarflexor moment, ankle power, and hip abductor moment in the Ponseti treated clubfeet [25,29-31,33]. The present study shows that there is no significant difference in ankle dorsiflexor moment and ankle plantarflexor moment between clubfeet treated with
Table 4

Outcomes Ponseti compared to surgery.

\begin{tabular}{clll}
\hline Outcome measure & $\begin{array}{l}\text { Difference Ponseti / } \\
\text { Surgery }\end{array}$ & Mean and SD & Study \\
\hline $\begin{array}{c}\text { Ankle plantarflexor } \\
\text { moment }\end{array}$ & No significant & P: $1.4 \pm 0.7 \mathrm{Nm} / \mathrm{kg}$ & Church \\
& difference & S: $1.4 \pm 0.5 \mathrm{Nm} / \mathrm{kg}$ & $2012[12]$ \\
& No significant & P: $0.97 \pm 0.2 \mathrm{Nm}$ & Duffy \\
Ankle power & difference & S: $0.89 \pm 0.2 \mathrm{Nm}$ & 2013 [29] \\
& Ponseti $<$ Surgery & P: $18.2 \pm 5.8 \mathrm{~W} / \mathrm{kg}$ & Church \\
& No significant & P: $2.8 \pm 0.7 \mathrm{~W} / \mathrm{kg}$ & $2012[12]$ \\
& difference & S: $2.5 \pm 0.6 \mathrm{~W}$ & Duffy \\
& No significant & P: $2.93 \pm 0.97 \mathrm{~W} / \mathrm{kg}$ & Jeans \\
& difference & S: $2.70 \pm 0.62 \mathrm{~W} / \mathrm{kg}$ & 2015 [24] \\
No significant & P: $0.15 \pm 0.5 \mathrm{~J}$ & Duffy \\
Ankle work & difference & S: $0.15 \pm 0.4 \mathrm{~J}$ & 2013 [29] \\
& & &
\end{tabular}

$\mathrm{P}=$ Ponseti.

$\mathrm{S}=$ Surgery.

surgery compared to patients treated with the Ponseti method $[12,24,29]$. The comparable results in gait kinetics between surgical and Ponseti treated clubfoot patients, are in line with other findings favouring the Ponseti method as preferred initial treatment for clubfeet [18]. This is due to its less-invasive character, wide applicability of the Ponseti method, the initial success rates, and lower relapse rates [12]. As such, even though differences between Ponseti treated clubfeet patients and healthy controls exist on several kinetic gait parameters, the Ponseti method should be considered as the gold standard for the treatment of clubfeet [18].

Most of the included studies in this review focused on the gait kinetics of the ankle. This is probably because the ankle is of main interest, since a clubfoot is about deformities of the foot. The main factor contributing to the impaired gait kinetics in children with clubfeet, remains unknown. In clubfeet foetuses abnormalities were seen in muscle fibers, connective tissue, tendons and the triceps surae [35]. Furthermore, other studies showed that children with clubfeet have smaller lower leg muscles, but also a limited ankle range of motion has been found [16,29,31,33]. Clubfeet patients who are treated with extensive surgery often show muscle weakness (especially in the gastroscoleus muscle) which can be linked to kinematic abnormalities [45]. In order to improve gait, problems such as lower muscle force and lower muscle power might be addressed with physiotherapy focusing on power training of the plantar flexors [36-38]. Although due to morphological differences training up to a complete normal level might not be feasible.

The question remains what the functional implications of the impaired gait kinetics are. Two studies have studied the relationship between gait analysis and gross motor function, which can be explained as movement and coordination of the large body parts, such as arms and legs. One study found mild differences in gait kinematics and kinetics in treated clubfeet compared to healthy controls, but differences in gross motor function rarely existed [39]. The other study found deficits in gross motor function and gait between the clubfoot and healthy control group, but the relationship between 3D gait analysis and gross motor skills was poor to moderate [34], indicating that impaired gait characteristics do not necessarily affect the gross motor skills of clubfeet patients. So overall functional implications are still unclear.

Other studies have looked at radiographic images to study the longterm results of treatment for clubfeet. In both surgically and Ponseti treated clubfeet osteoarthritis in their feet was found at age 16-34 $[10,21,32,40]$, although the percentage of occurrence differs between the studies. Osteoarthritis was found in several joints of the foot, including the subtalar, talonavicular, calcaneocuboid, naviculocuneiform, and tibiotalar joint [32,40]. This could imply that although no functional differences compared to healthy controls could be seen directly after treatment, long-term effects as a result of an altered gait 
pattern could be present. However, the relationship between osteoarthritic changes in the different joints of the foot and the kinetic parameters is unclear. Moreover, it remains unclear whether the higher grade of osteoarthritis in clubfeet is caused by the gait pattern or by other causes, including stiffness and weakness of the foot [41]. A more detailed 3D model of the foot will be necessary in combination with long-term follow up of the effects of the Ponseti treatment for clubfeet patients in terms of osteoarthritis.

The quality of a systematic review and meta-analysis is strongly related to the quality of the included studies. Although research with clubfeet patients is a fast growing research field, only nine studies could be included in this review. Due to the high variation in the reported variables, meta-analyses could only be performed for four variables, mostly related to the ankle joint. A big advantage of 3D gait analysis is that kinetics of the entire lower extremity can be evaluated and as such also compensatory mechanisms in hip and knee could be detected [6]. Future studies should therefore also include knee and hip kinetics. In order to facilitate comparison between studies, consistent presentation of the results is recommended. Since kinetics are highly dependent on velocity [6], walking speed should always be reported. Part of the explanation why healthy controls show higher joint moment and power than clubfeet patients could lie in the differences in speed. In a sixminute walking test, the majority of clubfeet patients -mostly treated with extensive surgery- showed a decreased walking speed compared to the patients' norm value [42]. In the included studies participants were instructed to walk at a self-selected speed, unfortunately information on the reached walking velocity was not provided. Furthermore, attention should be paid to the methodological quality and transparent description of the study design in order to limit the risk of bias. Another remark that has to be placed here is that overcorrected and recurrent feet may behave differently than feet that have been corrected perfectly and only once. Unfortunately, the included studies only provided limited information on the status of the included clubfeet.

An important issue in case of the analyses of bilateral data is the correlation between observations of the left and right side of one patient [43]. This issue has also been shown with respect to baseline severity in bilateral clubfeet patients, which was highly correlated between both sides [44]. Unfortunately, the majority of the included studies that could be included in this systematic review analysed the data based on the number of feet, combining data of both uni- and bilaterally affected patients. Lööf and colleagues presented separate results for uni- and bilateral affected clubfeet [33,34]. However, since the same set of controls was used, which violates the assumption of independence of observation within the meta-analyses, data of both clubfeet groups was combined and included in the meta-analyses as a single study. Although, average values differed slightly for the combined groups, overall results remained the same when addressing the uni- and bilateral clubfeet patients as two groups (e.g. Ponseti treated clubfeet patient showed lower peak ankle power, ankle abductor moment and GDI-Kinetics).

Overall, this review suggests that there are no significant differences in gait kinetics between clubfeet treated by extensive surgery compared to clubfeet treated with the Ponseti method. The Ponseti method is a method without extensive surgery, whereas a posteromedial release is. In general if two treatment modalities have the same outcome, the less invasive one is preferable. When comparing the gait kinetics of Ponseti treated clubfeet with healthy controls, the Ponseti treated clubfeet show impaired gait kinetics. Until now it remains unclear how functional limiting these differences are and if perhaps some of these issues could be addressed in targeted therapy for the patient.

\section{Declarations of interest}

None.

\section{Funding}

This research did not receive any specific grant from funding agencies in the public, commercial, or not-for-profit sectors.

\section{Acknowledgement}

We thank W.M. Bramer, information specialist from the Erasmus MC Rotterdam, for performing the literature search.

\section{Appendix A}

\section{Embase.com}

(clubfoot/de OR 'pes equinovarus'/exp OR (clubfoot OR clubfeet OR club-foot OR club-feet OR talipes OR equinovarus OR equino-varus):ab,ti) AND (therapy/exp OR 'treatment outcome'/exp OR surgery/ exp OR therapy:lnk OR surgery:Ink OR 'clinical trial'/exp OR relapse/ exp OR 'follow up'/exp OR 'evaluation study'/exp OR rehabilitation/exp OR rehabilitation:lnk OR 'single blind procedure'/exp OR 'double blind procedure'/exp OR 'triple blind procedure'/exp OR (surg* OR therap* OR treat* OR ponseti OR cast* OR outcome* OR nonoperat* OR nonsurg* OR comprehensive* OR release* OR interven* OR management* OR conservativ* OR trial* OR random* OR correct* OR relaps* OR recur* OR (follow* NEXT/1 up*) OR followup* OR evaluat* OR rehabilitat* OR ((double OR single OR triple) NEXT/1 (blind* OR mask*)) OR Physiotherap*):ab,ti) AND (gait/exp OR 'gait disorder'/exp OR electromyogram/exp OR biomechanics/exp OR 'pressure measurement'/de OR (gait OR ((force OR forces OR pressure*) NEAR/3 (distribut* OR peak OR foot OR measur* OR plantar*)) OR EMG OR pedobarograph* OR electromyogr* OR Biomechanic*))

\section{References}

[1] I.V. Ponseti, The treatment of congenital clubfoot, J. Orthop. Sports Phys. Ther. 20 (1994) 1.

[2] K. Gray, V. Pacey, P. Gibbons, D. Little, J. Burns, Interventions for congenital talipes equinovarus (clubfoot), Cochrane Database Syst. Rev. (2014) CD008602.

[3] A. Pirani, H.K. Outerbridge, B. Sawatsky, K. Stothers, A reliable method of clinically evaluating a virgin clubfoot evaluation, 21st SICOT Conference (1999).

[4] A. Dimeglio, H. Bensahel, P. Souchet, P. Mazeau, F. Bonnet, Classification of clubfoot, J. Pediatr. Orthop. B 4 (1995) 129-136.

[5] A. Graf, K.W. Wu, P.A. Smith, K.N. Kuo, J. Krzak, G. Harris, Comprehensive review of the functional outcome evaluation of clubfoot treatment: a preferred methodology, J. Pediatr. Orthop. B 21 (2012) 20-27.

[6] T.N. Theologis, Gait analysis, in: M. Benson, J. Fixsen, M. Macnicol, K. Parsch (Eds.), Children'S Orthopaedics and Fractures, Springer London, London, 2009, pp. 67-74.

[7] I. Jonkers, S. Delp, C. Patten, Capacity to increase walking speed is limited by impaired hip and ankle power generation in lower functioning persons post-stroke, Gait Posture 29 (2009) 129-137.

[8] I. Pacifici, M. Galli, A.F. Kleiner, F. Corona, G. Coghe, E. Marongiu, et al., The required Coefficient of Friction for evaluating gait alterations in people with Multiple Sclerosis during gait, Mult. Scler. Relat. Disord. 10 (2016) 174-178.

[9] K. Desloovere, G. Molenaers, L. Van Gestel, C. Huenaerts, A. Van Campenhout, B. Callewaert, et al., How can push-off be preserved during use of an ankle foot orthosis in children with hemiplegia? A prospective controlled study, Gait Posture 24 (2006) 142-151.

[10] J.H. van Gelder, A.G. van Ruiten, J.D. Visser, P.G. Maathuis, Long-term results of the posteromedial release in the treatment of idiopathic clubfoot, J. Pediatr. Orthop. 30 (2010) 700-704.

[11] B. Banskota, A.K. Banskota, R. Regmi, T. Rajbhandary, O.P. Shrestha, D.A. Spiegel, The Ponseti method in the treatment of children with idiopathic clubfoot presenting between five and ten years of age, Bone Joint J. 95-B (2013) 1721-1725.

[12] C. Church, J.A. Coplan, D. Poljak, A.M. Thabet, D. Kowtharapu, N. Lennon, et al., A comprehensive outcome comparison of surgical and Ponseti clubfoot treatments with reference to pediatric norms, J. Child. Orthop. 6 (2012) 51-59.

[13] C. Beyaert, T. Haumont, J. Paysant, P. Lascombes, J.M. Andre, The effect of inturning of the foot on knee kinematics and kinetics in children with treated idiopathic clubfoot, Clin. Biomech. (Bristol, Avon) 18 (2003) 670-676.

[14] T. Alkjaer, E.N. Pedersen, E.B. Simonsen, Evaluation of the walking pattern in clubfoot patients who received early intensive treatment, J. Pediatr. Orthop. 20 (2000) 642-647.

[15] H.H. Muratli, C. Dagli, G. Yavuzer, L. Celebi, A. Bicimoglu, Gait characteristics of patients with bilateral club feet following posteromedial release procedure, J. 
Pediatr. Orthop. B 14 (2005) 206-211.

[16] T.N. Theologis, M.E. Harrington, N. Thompson, M.K. Benson, Dynamic foot movement in children treated for congenital talipes equinovarus, J. Bone Joint Surg. Br. 85 (2003) 572-577.

[17] L. Shabtai, S.C. Specht, J.E. Herzenberg, Worldwide spread of the Ponseti method for clubfoot, World J. Orthop. 5 (2014) 585-590.

[18] A.T. Besselaar, R.J.B. Sakkers, H.A. Schuppers, M. Witbreuk, E. Zeegers, J.D. Visser, et al., Guideline on the diagnosis and treatment of primary idiopathic clubfoot, Acta Orthop. 88 (2017) 305-309.

[19] E.B. Zwick, T. Kraus, C. Maizen, G. Steinwender, W.E. Linhart, Comparison of Ponseti versus surgical treatment for idiopathic clubfoot: a short-term preliminary report, Clin. Orthop. Relat. Res. 467 (2009) 2668-2676.

[20] J.A. Morcuende, L.A. Dolan, F.R. Dietz, I.V. Ponseti, Radical reduction in the rate of extensive corrective surgery for clubfoot using the Ponseti method, Pediatrics 113 (2004) 376-380.

[21] D.M. Cooper, F.R. Dietz, Treatment of idiopathic clubfoot. A thirty-year follow-up note, J. Bone Joint Surg. Am. 77 (1995) 1477-1489.

[22] M. Svehlik, U. Floh, G. Steinwender, M. Sperl, M. Novak, T. Kraus, Ponseti method is superior to surgical treatment in clubfoot - Long-term, randomized, prospective trial, Gait Posture 58 (2017) 346-351.

[23] M. Offringa, W. Assendelft, R. Scholten, Inleiding in Evidence-based Medicine. Klinisch Handelen Gebaseerd Op Bewijsmateriaal, Bohn, Stafleu, van Loghum, Houten, 2013.

[24] K.A. Jeans, A.L. Erdman, C.H. Jo, L.A. Karol, A longitudinal review of gait following treatment for idiopathic clubfoot: gait analysis at 2 and 5 years of age, J. Pediatr. Orthop. 36 (2016) 565-571.

[25] E. Manousaki, T. Czuba, G. Hagglund, L. Mattsson, H. Andriesse, Evaluation of gait, relapse and compliance in clubfoot treatment with custom-made orthoses, Gait Posture 50 (2016) 8-13.

[26] A. Kolb, M. Willegger, R. Schuh, A. Kaider, C. Chiari, R. Windhager, The impact of different types of talus deformation after treatment of clubfeet, Int. Orthop. 41 (2017) 93-99.

[27] A. Liberati, D.G. Altman, J. Tetzlaff, C. Mulrow, P.C. Gotzsche, J.P. Ioannidis, et al., The PRISMA statement for reporting systematic reviews and meta-analyses of studies that evaluate healthcare interventions: explanation and elaboration, BMJ 339 (2009) b2700.

[28] L. Shamseer, D. Moher, M. Clarke, D. Ghersi, A. Liberati, M. Petticrew, et al., Preferred reporting items for systematic review and meta-analysis protocols (PRISMA-P) 2015: elaboration and explanation, BMJ. 349 (2015) g7647.

[29] C.M. Duffy, J.J. Salazar, L. Humphreys, B.C. McDowell, Surgical versus Ponseti approach for the management of CTEV: a comparative study, J. Pediatr. Orthop. 33 (2013) 326-332.

[30] L.A. Karol, K. Jeans, R. ElHawary, Gait analysis after initial nonoperative treatment for clubfeet: intermediate term followup at age 5, Clin. Orthop. Relat. Res. 467 (2009) 1206-1213.

[31] G.T. Mindler, A. Kranzl, C.A. Lipkowski, R. Ganger, C. Radler, Results of gait analysis including the Oxford foot model in children with clubfoot treated with the Ponseti method, J. Bone Joint Surg. Am. 96 (2014) 1593-1599.

[32] P.A. Smith, K.N. Kuo, A.N. Graf, J. Krzak, A. Flanagan, S. Hassani, et al., Long-term results of comprehensive clubfoot release versus the Ponseti method: which is better? Clin. Orthop. Relat. Res. 472 (2014) 1281-1290.

[33] E. Loof, H. Andriesse, M. Andre, S. Bohm, E.W. Brostrom, Gait in 5-year-old children with idiopathic clubfoot: a cohort study of 59 children, focusing on foot involvement and the contralateral foot, Acta Orthop. 87 (2016) 522-528.

[34] E. Loof, H. Andriesse, M. Andre, S. Bohm, M.D. Iversen, E.W. Brostrom, Gross motor skills in children with idiopathic clubfoot and the association between gross motor skills, foot involvement, gait, and foot motion, J. Pediatr. Orthop. (2017).

[35] E. Ippolito, I.V. Ponseti, Congenital club foot in the human fetus. A histological study, J. Bone Joint Surg. Am. 62 (1980) 8-22.

[36] Y. Kobayashi, Y. Ueyasu, Y. Yamashita, R. Akagi, Effects of 4 weeks of explosivetype strength training for the plantar flexors on the rate of torque development and postural stability in elderly individuals, Int. J. Sports Med. 37 (2016) 470-475.

[37] A. Ferri, G. Scaglioni, M. Pousson, P. Capodaglio, J. Van Hoecke, M.V. Narici, Strength and power changes of the human plantar flexors and knee extensors in response to resistance training in old age, Acta Physiol. Scand. 177 (2003) 69-78.

[38] J. Brincks, J.F. Nielsen, Increased power generation in impaired lower extremities correlated with changes in walking speeds in sub-acute stroke patients, Clin. Biomech. (Bristol, Avon) 27 (2012) 138-144.

[39] L.A. Karol, K.A. Jeans, K.A. Kaipus, The relationship between gait, gross motor function, and parental perceived outcome in children with clubfeet, J. Pediatr. Orthop. 36 (2016) 145-151.

[40] M.B. Dobbs, R. Nunley, P.L. Schoenecker, Long-term follow-up of patients with clubfeet treated with extensive soft-tissue release, J. Bone Joint Surg. Am. 88 (2006) 986-996.

[41] J.E. Herzenberg, C. Radler, N. Bor, Ponseti versus traditional methods of casting for idiopathic clubfoot, J. Pediatr. Orthop. 22 (2002) 517-521.

[42] J.J. Lohle-Akkersdijk, E.A. Rameckers, H. Andriesse, I. de Reus, R.H. van Erve, Walking capacity of children with clubfeet in primary school: something to worry about? J. Pediatr. Orthop. B 24 (2015) 18-23.

[43] H. Menz, Two feet, or one person? Problems associated with statistical analysis of paired data in foot and ankle medicine, Foot (2004) $2-5$.

[44] K. Gray, P. Gibbons, D. Little, J. Burns, Bilateral clubfeet are highly correlated: a cautionary tale for researchers, Clin. Orthop. Relat. Res. 472 (2014) 3517-3522.

[45] L.A. Karol, M.C. Concha, C.E. Johnston, Gait analysis and muscle strength in children with surgically treated clubfeet, J. Pediatr. Orthop. 17 (1997) 790-795. 